\title{
Avaliação das condições higiênicas de escolas de ensino infantil e fundamental por meio da aplicação de listas de verificação
}

\author{
Lizahélen Morais da Silva ${ }^{1}$, Carla Cristina Bauermann Brasil ${ }^{2}$, Anne y Castro Marques ${ }^{3}$, Joice \\ Trindade Silveira ${ }^{4}$, Fernanda Aline de Moura ${ }^{5}$, Coryna Sanchotene Martini ${ }^{6}$ e Marilei Bertão \\ Schiavo $^{6}$
}

O objetivo deste estudo foi avaliar as condições higiênicas de escolas de ensino infantil e fundamental do município Itaqui - RS. O estudo avaliou 12 escolas públicas municipais, sendo seis de educação infantil e seis de ensino fundamental. Foram elaboradas listas de verificação em boas práticas para as unidades de alimentação e nutrição escolares (UANEs), sendo duas listas completas (LVBPC) - aplicadas no primeiro e último acompanhamento - e duas listas reduzidas (LVBPR) aplicadas nos sete acompanhamentos intermediários. As listas foram fundamentadas nas legislações sanitárias vigentes, sendo aplicadas in loco semanalmente, em turnos alternados e sem aviso prévio às escolas. A classificação das UANEs foi adaptada de acordo com o Centro Colaborador em Alimentação e Nutrição do Escolar (CECANE) segundo o grau de risco sanitário. A média de adequação geral das escolas infantis foi de 36,13\% e 35,28\% para as LVBPC e LVBPR, respectivamente. Enquanto a média de adequação geral das escolas fundamentais em relação às boas práticas foi de 40,19\% e 40,92\% para as listas completas e reduzidas, respectivamente. Com isso, percebe-se a necessidade de implantação de ações preventivas nessas UANEs, uma vez que foram observados procedimentos que podem comprometer a alimentação escolar do ponto de vista higiênico-sanitário.

Palavras-chave: alimentação escolar, Boas Práticas de Fabricação, legislação sanitária, lista de verificação.

\section{Evaluation of hygienic conditions of infant and primary schools by implementing checklists}

The aim of this study was to evaluate the hygienic conditions of preschools and elementary schools in the city of Itaqui, RS state. The study evaluated 12 public schools, six of each group. Checklists about good practices for school feeding and nutrition (UANEs) were applied, being two complete lists (LVBPC) - applied on the first and

\footnotetext{
${ }^{1}$ Graduada em Nutrição pela Universidade Federal do Pampa (UNIPAMPA). Endereço para correspondência: Rua Visconde de Mauá, no 905, Cidade Alta, CEP 97650-000, Itaqui - RS. Telefone para contato: (55)96509225. E-mail: lizaitaqui@hotmail.com

2 Profa. Dra. em Ciência e Tecnologia de Alimentos, Docente da Universidade Federal de Santa Maria (UFSM) - Campus de Palmeira das Missões.

${ }^{3}$ Profa. Dra. em Alimentos e Nutrição, Docente da Universidade Federal do Pampa (UNIPAMPA) - Campus Itaqui - RS.

${ }^{4}$ Profa. Doutoranda em Educação em Ciências - Química da Vida e Saúde, Docente da Universidade Federal do Pampa (UNIPAMPA) - Campus Itaqui - RS

${ }^{5}$ Profa. Dra. em Ciência e Tecnologia de Alimentos, Docente da Universidade Federal do Pampa (UNIPAMPA) - Campus Itaqui - RS

${ }^{6}$ Graduada em Nutrição, Nutricionista da Secretaria Municipal de Educação (SME), Itaqui - RS
} 
last visits - and two short lists (LVBPR) applied in the seven intermediate visits. The lists were based on current health legislation and applied in loco weekly, not scheduled and on alternated shifts. The classification of UANEs according to the degree of health risk was in accordance with the specifications of the Collaborating Center for Students' Food and Nutrition (CECANE). The average overall adequacy of preschools was 36.13\% and 35.28\% for LVBPC and LVBPR, respectively, while the average overall adequacy of the elementary schools in relation to the good practices was $40.19 \%$ and $40.92 \%$ for the complete and short lists, respectively. Preventive actions in these UANEs are needed to avoid the health risk caused by poor hygienic-sanitary conditions.

Keywords: school food, Good Manufacturing Practices, sanitary legislation, checklist.

\section{INTRODUÇÃO}

As refeições produzidas nas unidades de alimentação e nutrição escolares (UANEs) devem atender às necessidades nutricionais dos alunos, oferecendo alimentação adequada sob os aspectos sensoriais e nutricionais, mas, sobretudo, devem produzir alimentos seguros quanto às condições higiênico-sanitárias, garantindo assim a proteção e promoção da saúde dos escolares [1].

O Programa Nacional de Alimentação Escolar (PNAE) foi implantado em 1979 no Brasil, dando continuidade a campanha da merenda escolar criada em 1955 [2]. O PNAE é considerado o maior programa de alimentação escolar em atividade na rede de ensino público no país, servindo mais de 37 milhões de refeições diariamente. O programa visa atender às necessidades nutricionais dos alunos durante a permanência em sala de aula, favorecendo a formação de hábitos alimentares saudáveis, a partir do fornecimento de alimentação saudável e segura do ponto de vista higiênico-sanitário [3,4].

As boas práticas (BP) são definidas como regras ou princípios básicos para o manuseio higiênico dos alimentos, adotados com a finalidade de controlar, prevenir, eliminar ou reduzir a contaminação física, química ou biológica, desde a matéria-prima até o produto final, assegurando não só a oferta de alimentos adequados ao consumo humano, mas, principalmente, a saúde do consumidor [5,9. As BP devem ser aplicadas em todas as etapas que possam afetar a segurança do alimento, tais como: ambiente, instalações, equipamentos, manipuladores, fornecedor, recebimento, produção, armazenamento, abastecimento de água, esgoto e lixo, dentre outros.

As BP são regidas pela Resolução RDC no 216 de 15 de setembro de 2004 e, no Rio Grande do Sul, pela Portaria no 78, de 30 de janeiro de 2009 ambas para serviços de alimentação [5,6]. Ainda, a Portaria no 817 de 10 de maio de 2013, contem diretrizes nacionais para a categorização dos serviços de alimentação, segundo critérios sanitários $[7]$.

O cumprimento das legislações sanitárias nos serviços de alimentação é imprescindível, principalmente em UANEs, que oferecem refeições a crianças e adolescentes em fase de desenvolvimento. Caso os procedimentos relacionados às $\mathrm{BP}$ de manipulação de alimentos não sejam cumpridos, eles podem ocasionar doenças transmitidas por alimentos (DTAs), causadas principalmente pela ingestão de alimentos ou bebidas que foram afetados por microorganismos patogênicos.

A origem da contaminação pode ser bacteriana, viral ou parasitária, além de envenenamentos causados por toxinas naturais, produtos químicos ou metais pesados. Existem mais de 250 tipos de DTAs, e entre as principais formas de contaminação, destacam-se a manipulação e a conservação inadequada dos alimentos ${ }^{[8]}$.

No Brasil, de acordo com a Secretaria de Vigilância Sanitária, no período compreendido entre 2000 a 2014, foram notificados ao Ministério da Saúde 9.942 surtos de DTAs, sendo que as escolas de educação infantil e fundamental ocupam a quarta posição com 8,60\%, merecendo atenção dos responsáveis [?]. Portanto, as DTAs constituem uma das principais preocupações relacionadas à saúde pública, tendo uma maior relevância quando se trata de alimentos produzidos em UANEs [10].

Diversas estratégias podem ser utilizadas para avaliar as condições higiênicas de UANEs, sendo a lista de verificação em boas práticas o método mais utilizado, por ser uma técnica prática, de baixo custo e 
eficaz. Porém, a falta de um instrumento padronizado específico para as UANEs faz com que diversas listas de verificação sejam criadas e adaptadas, sem contemplarem todos os critérios de avaliação necessários, de acordo com a legislação sanitária [11].

A verificação das condições higiênicas do preparo da alimentação escolar, as ações corretivas das não conformidades encontradas nas diferentes etapas do processo produtivo de alimentos e a adoção de medidas preventivas em UANEs podem garantir o fornecimento de alimento seguro, promovendo assim a qualidade higiênico-sanitária dos alimentos e a saúde dos escolares ${ }^{[12]}$.

Considerando que dados sobre acompanhamento do processo produtivo da alimentação escolar durante um determinado período de tempo ainda são escassos na literatura, torna-se relevante a pesquisa para conhecer as reais condições higiênicas das escolas municipais de ensino infantil e fundamental, uma vez que o acompanhamento proporciona um diagnóstico mais fidedigno, para que possam ser tomadas medidas de adequação dessas UANEs. O objetivo deste estudo foi avaliar as condições higiênicas de escolas municipais de ensino infantil e fundamental por meio da aplicação de diferentes listas de verificação baseadas em legislações vigentes.

\section{METODOLOGIA}

O presente estudo caracteriza-se como descritivo, realizado nas UANEs do município de Itaqui - RS, no período de março a dezembro de 2014. A amostra foi composta por 12 instituições da rede municipal de ensino, sendo seis escolas de educação infantil (EMEIs) e seis de ensino fundamental (EMEFs).

Os responsáveis pelas UANEs foram contatados para exposição dos objetivos e metodologia do projeto. Aqueles que aceitaram participar assinaram um termo de autorização para o desenvolvimento da pesquisa. Como critério de inclusão, participaram da pesquisa escolas públicas municipais de ensino infantil e fundamental, e como critério de exclusão, as escolas públicas municipais da zona rural. As UANEs foram identificadas por letras (A, B, C, D, E e F) visando o sigilo das mesmas.
Para a coleta de dados, o grupo de pesquisa desenvolveu quatro listas de verificação em boas práticas (LVBP), duas para as escolas municipais de ensino infantil e duas para as escolas municipais de ensino fundamental, sendo duas listas completas (LVBPC) e duas reduzidas (LVBPR).

Em cada UANE, para fins de diagnóstico, inicialmente foi aplicada a lista completa, destacando as categorias relacionadas às condições higiênicas, estruturais, manipulação de alimentos, documentação, registro e responsabilidade técnica. Nos sete acompanhamentos intermediários, foram aplicadas as listas reduzidas focando no processo produtivo da alimentação escolar, tendo por objetivo realizar o monitoramento destas etapas ao longo do semestre letivo.

No último acompanhamento realizado nas EMEIs e EMEFs foi aplicada novamente a LVBPC, a fim de verificar se ao longo do desenvolvimento da pesquisa houve modificações nas boas práticas das UANEs, tendo como propósito um diagnóstico real durante o período da coleta de dados. Assim, foram aplicadas nove LVBP nas UANEs, sendo duas listas completas e sete reduzidas. Todas as listas desenvolvidas foram fundamentadas na RDC no 216/2004, na Portaria no 78/2009, bem como na Portaria no $817 / 2013[5,6,7]$.

Ainda, foi aferida as temperaturas dos alimentos prontos para o consumo (quente e frio) através do termômetro digital de profundidade (tipo espeto) da marca Thermometer modelo Precision com sensibilidade de $-50^{\circ} \mathrm{C}$ a $+300^{\circ} \mathrm{C}$. A aferição das temperaturas dos alimentos foi realizada em três etapas: alimento pronto (logo após a cocção), na distribuição aos escolares e antes do término das refeições (final da distribuição).

As LVBPs foram aplicadas durante os meses de junho a novembro de 2014 por discentes do Curso de Nutrição da Universidade Federal do Pampa (UNIPAMPA), previamente capacitados por docentes responsáveis pela pesquisa. Os discentes foram divididos em duplas para aplicação das LVBP nas 12 UANEs. Foram realizadas nove visitas em cada UANE, sendo duas aplicações da LVBPC e sete da LVBPR, para obtenção do diagnóstico a longo prazo. As LVBPs foram aplicadas in loco, semanalmente (segunda à sexta-feira), em turnos alternados (manhã e tarde), sem aviso prévio às escolas. 
A LVBPC das EMEIs possuía 10 categorias, e a LVBPR oito categorias. A LVBPC das EMEFs possuía 12 categorias, e a LVBPR oito categorias.

Foram mantidas nas LVBPRs aplicadas somente as categorias e itens que poderiam ter variações no decorrer da pesquisa, principalmente aqueles relacionados ao processo produtivo da alimentação escolar (Tabela 1).

Tabela 1. Itens da lista de verificação em boas práticas completa e reduzida das escolas municipais de educação infantil e ensino fundamental.

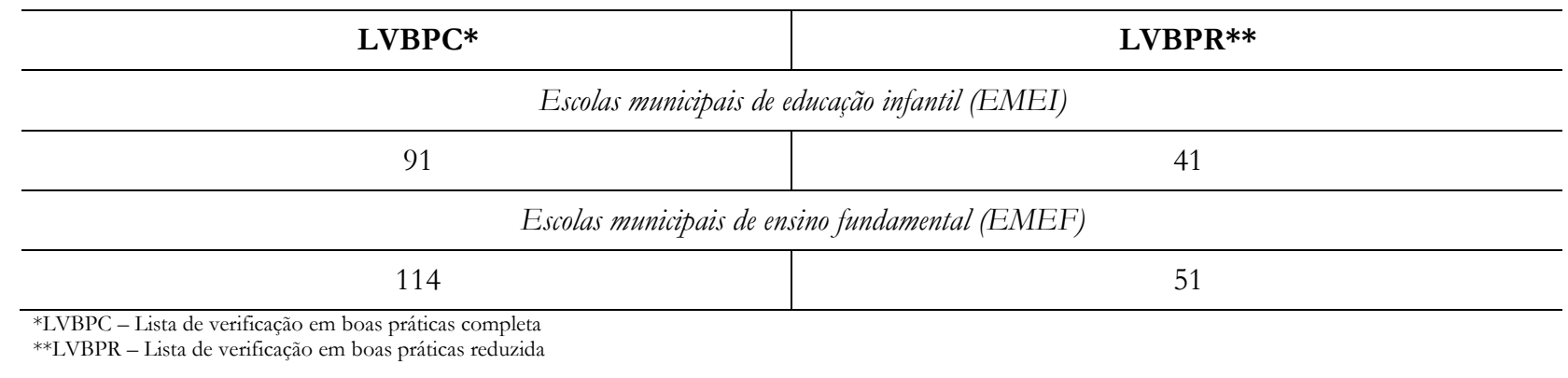

Nas LVBPs foram atribuídos valores às diferentes respostas (Conforme e Não Conforme). Para as respostas Conforme $(\mathrm{C})$, foi atribuído o valor de 1 (um) ponto e as respostas Não Conforme (NC) receberam nota 0 (zero).

O número de respostas Não Aplicáveis (NA) e Não Observados (NO), obtidos nas UANEs, foram subtraídos do total de itens, não sendo, portanto, computados na soma final. Além disso, a lista de verificação possuía um espaço destinado a observações realizadas pelos avaliadores.

O percentual de adequação das UANEs foi classificado conforme o grau de risco sanitário quanto às boas práticas, sendo adaptado de acordo com o Centro Colaborador em Alimentação e Nutrição do Escolar da Universidade Federal do Rio Grande do Sul (CECANE/UFRGS) ${ }^{[13]}$.

Os dados coletados foram digitados e tabulados com o auxílio do programa Microsoft Office Excel, versão 2007 e as figuras formuladas por meio do programa GraphPad Prism versão 5.0. Os dados foram submetidos à análise estatística descritiva simples (média e percentual de conformidade), com auxílio do programa Statistica versão 7.0.
Após a aplicação da lista de verificação e diagnóstico do local quanto às BP foi elaborado um relatório descritivo com a classificação das UANEs, onde foram descritas as não conformidades encontradas durante a realização do projeto. Logo após, os resultados foram entregues para as nutricionistas da Secretaria Municipal de Educação (SME) do município, para que as mesmas tivessem conhecimento sobre as condições higiênicas dessas UANEs, buscando a otimização do trabalho que já vem sendo desenvolvido pelas nutricionistas nas escolas do município.

\section{RESULTADOS E DISCUSSÃO}

\section{Escolas Municipais de Educação Infantil (EMEIs)}

\section{Classificação geral - LVBPC:}

A média de adequação geral em relação as boas práticas das seis EMEIs avaliadas foi de 33,14\% na aplicação inicial e 39,12\% na aplicação final da LVBPC, sendo classificadas em risco sanitário alto (26-50\%), estando abaixo de 76\% de adequação, conforme recomendação preconizada pela legislação sanitária [5]. 
Stedefeldt et al. [11], em um estudo da Universidade Federal de São Paulo (UNIFESP) de Santos (SP), sobre a validação de um instrumento de avaliação de BP em UANEs desenvolveram a classificação do CECANE/UFRGS [13], evidenciando que os critérios de pontuação em listas de verificação podem estimar com maior precisão o risco sanitário real observado.

$\mathrm{Na}$ avaliação inicial e final da LVBPC das EMEIs, todas as UANEs apresentaram aumento nos percentuais de adequação (Figura 1), no entanto, a escola $\mathrm{C}$ obteve um aumento de $14,77 \%$, seguida da escola D com 8,68\%, e da escola F com 6,11\%. Estas escolas apresentaram aumento nas categorias relacionadas a edificações e instalações; higienização de equipamentos, móveis e utensilios; preparação do alimento; armazenamento, transporte e exposição do alimento.

Ao mesmo tempo em que, as escolas $\mathrm{D}$ e $\mathrm{F}$ apresentaram aumento nas categorias relacionadas ao abastecimento de água e manipuladores de alimentos. Somente a escola $\mathrm{C}$ apresentou aumento na categoria matéria-prima, ingredientes e embalagens e a escola $\mathrm{F}$ na categoria controle integrado de vetores e pragas urbanas.

Apesar dos percentuais de adequação em relação as BP terem aumentado nas UANEs, entre a aplicação inicial e final da LVBPC, os mesmos não modificaram sua classificação sanitária.

Figura 1. Percentual de adequação geral da lista de verificação em boas práticas completa das escolas municipais de educação infantil.

\section{Percentual de adequação da LVBPC por categoria:}

$\mathrm{Na}$ avaliação geral da LVBPC das seis EMEIs por categoria, a média da aplicação inicial foi de 39,73\% e aplicação final 44,93\%, ambas classificadas como alto risco sanitário (26-50\%) de acordo com o percentual de adequação do CECANE/UFRGS [13].

As categorias que apresentaram aumento no percentual de adequação entre a aplicação inicial e final da lista completa foram referentes ao armazenamento, transporte e exposição do alimento preparado, higienização de equipamentos, móveis e utensilios e edificações e instalações, com aumento de 23,89\%, $15,12 \%$ e $7,31 \%$, respectivamente (Tabela 2). Esses aumentos nos percentuais de adequação se dão por melhorias e adequações das UANEs constatadas no decorrer da coleta dos dados.

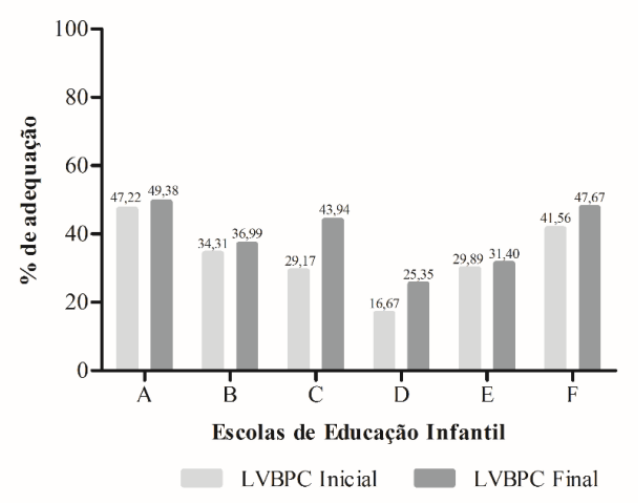


Tabela 2. Percentual médio de adequação da lista de verificação em boas práticas completa por categoria das escolas municipais de educação infantil.

\begin{tabular}{l|c|c}
\hline \multicolumn{1}{c|}{ Categorias } & $\begin{array}{c}\text { Aplicação Inicial } \\
(\%)\end{array}$ & $\begin{array}{c}\text { Aplicação Final } \\
(\%)\end{array}$ \\
\hline 1. Edificações e instalações & 25,25 & 32,56 \\
2. Higienização de equipamentos, móveis e utensílios & 21,55 & 36,67 \\
3. Abastecimento de água & 91,67 & 97,22 \\
4. Manipuladores de alimentos & 33,96 & 39,39 \\
5. Matéria-prima, ingredientes e embalagens & 37,22 & 33,33 \\
6. Preparação do alimento & 41,27 & 40,40 \\
7. Armazenamento, transporte e exposição do alimento preparado & 32,50 & 56,39 \\
8. Lactário & 0,00 & 5,00 \\
9. Controle integrado de vetores e pragas urbanas & 75,00 & 75,00 \\
10. Documentação, registro e responsabilidade & 38,89 & 33,33 \\
\hline \multicolumn{1}{c}{ Média } & 39,73 & 44,93 \\
\hline
\end{tabular}

Em relação à categoria de armazenamento, transporte e exposição do alimento preparado, todas as UANEs obtiveram aumento nos percentuais de adequação entre aplicação inicial e final da lista de verificação em boas práticas, contudo a escola $\mathrm{F}$ apresentou um aumento de $26,67 \%$. A exposição dos alimentos preparados melhorou no que se refere ao tempo e temperatura da refeição desde o preparo até a distribuição aos escolares, pois as temperaturas se mantinham $\geq 60^{\circ} \mathrm{C}$ para alimentos quentes e $\leq 5^{\circ} \mathrm{C}$ para alimentos frios conforme preconiza a legislação [5]. A aplicação de medidas de controle rigoroso da temperatura, promovendo a segurança dos alimentos, desde o recebimento até o consumo, é uma forma de minimizar o risco de ocorrência de DTAs.

A higienização de equipamentos, móveis e utensilios em todas as UANEs apresentaram aumento nos percentuais de adequação entre a aplicação inicial e final da lista, entretanto a escola $\mathrm{F}$ obteve um aumento de $36,37 \%$ comparado às demais EMEIs. Esse resultado pode ter ocorrido, pois, no decorrer da pesquisa, foram sanadas dúvidas dos manipuladores de alimentos com relação à higienização correta do local de manipulação, bem como o preenchimento de planilhas dos procedimentos operacionais padronizados de limpeza e sanitização das instalações, equipamentos e utensilios. Ressalta-se que o objetivo do trabalho não foi realizar capacitações, mas, durante a permanência dos pesquisadores nas escolas, havia conversas informais com os colaboradores das UANEs, o que pode ter contribuído com o aumento do percentual de adequação desta categoria.

A escola D apresentou um aumento de $25 \%$ com relação às demais escolas, pois foi realizada reforma estrutural na mesma. Das EMEIs participantes da pesquisa, somente a escola A não apresentou aumento nos percentuais de adequação entre a aplicação inicial e final da LVBPC em relação à categoria edificações e instalações. Kochansky et al. [14], em um estudo que avaliou as condições microbiológicas em uma unidade de alimentação e nutrição, relataram que investimentos em estrutura adequada e adoção de medidas de higienização podem reverter em maior segurança microbiológica nos estabelecimentos de alimentação coletiva.

As categorias que obtiveram redução significativa no percentual de adequação entre a aplicação inicial e final da lista foram referentes à documentação, registro e responsabilidade e matériaprima, ingredientes e embalagens, com redução de $5,56 \%$ e $3,89 \%$, respectivamente. Essa redução se deve a não adoção de medidas corretivas e preventivas no processo produtivo de alimentos e a rotatividade de 
colaboradores terceirizados na produção da alimentação escolar.

Em relação à categoria documentação, registro e responsabilidade, todas as EMEIs possuíam Manual de Boas Práticas (MBP) e Procedimentos Operacionais Padronizados (POPs), que foram elaboradas pelas nutricionistas do município através do Guia de Instruções - Ferramentas para as Boas Práticas na Alimentação Escolar do CECANE/UFRGS [13], porém os mesmos não estavam disponíveis aos colaboradores e órgãos fiscalizadores.

$\mathrm{Na}$ categoria referente à responsabilidade técnica, alguns manipuladores de alimentos não eram devidamente capacitados para exercerem as funções designadas nas UANEs e nem todos foram contratados por meio de concurso público. Há os colaboradores terceirizados do processo seletivo simplificado, muitos sem experiência e conhecimento técnico-prático, os quais permanecem de três a cinco meses nas UANEs, comprometendo a garantia de um trabalho contínuo e acarretando em prejuízos do processo produtivo de alimentos.

As escolas C, D e E não obtiveram percentual de adequação na aplicação inicial e final da lista, sendo que a EMEI A reduziu 33,33\% nas referidas aplicações e apenas a escola $\mathrm{F}$ apresentou 100\% de adequação na aplicação inicial e final. A ausência desses documentos faz com que não exista padronização do serviço, prejudicando a eficácia e qualidade da produção da alimentação escolar. Os MBPs e POPs devem estar acessíveis aos manipuladores de alimentos e serem implementados na prática diária da produção de alimentos nas UANEs.

$\mathrm{Na}$ categoria relacionada à matéria-prima, ingredientes e embalagens a EMEI F apresentou uma redução significativa de $66,67 \%$ no percentual de adequação entre a aplicação inicial e final da LVBPC.

$O$ recebimento de gêneros alimentícios nem sempre era possível de ser monitorado, no entanto, quando observado, o mesmo não era realizado em área limpa e protegida e devidamente inspecionado pelas colaboradoras, conforme orientação das nutricionistas da SME. Além disso, é importante destacar que nenhuma EMEI possuía termômetro para o controle da temperatura do recebimento de matérias-primas. Cardoso et al. [15], em um estudo realizado em Salvador (BA) questionam a segurança na produção de alimentos em 235 escolas (estaduais $=97$ e municipais $=138$ ) e mencionam que a inadequação de várias UANEs quanto ao local de recepção dos gêneros alimentícios merece destaque, uma vez que $98,30 \%(n=231)$ não dispunham de área adequada, e que em nenhuma das UANEs foi observada a existência de termômetros para o monitoramento da temperatura dos produtos recebidos, mostrando dados semelhantes com o presente estudo.

As demais categorias não apresentaram alterações no percentual de adequação entre às duas aplicações da LVBPC.

É importante salientar que as UANEs não possuíam lactário, no entanto, nesta pesquisa foram considerados itens relacionados à estrutura, que foram extraídas da LVBPR. Os itens referentes ao recebimento, higienização e temperatura de armazenamento das mamadeiras foram considerados.

Dessa forma, pode-se observar que as mamadeiras eram preparadas pelos manipuladores de alimentos nas cozinhas das escolas, logo no início do expediente, e eram transportadas aos berçários permanecendo em temperatura ambiente na sala de aula por longo período de tempo (3h).

Foram encontrados dados semelhantes a essa pesquisa em escolas de educação infantil $(n=5)$ estudadas por Oliveira et al. [16], que avaliaram as condições higiênico-sanitárias das cozinhas de creches públicas e filantrópicas de São Paulo (SP), e observaram que a área definida erroneamente como lactário era um espaço, próximo ao berçário, destinado à distribuição da alimentação do lactente. A produção dessa alimentação era realizada na cozinha, em um espaço definido para o preparo de mamadeiras e da alimentação que era oferecida às crianças menores de dois anos.

Segundo Silva Júnior [17], o lactário deve possuir distinção entre área limpa e suja, com acesso independente à área limpa, através do vestiário de barreira. Ainda, deve conter uma sala destinada à recepção e higienização de mamadeiras e outros utensílios, a mesma deve possuir um guichê, para o recebimento do material usado; uma sala para o preparo e envase de fórmulas lácteas e não lácteas e para estocagem e distribuição das fórmulas, além da área de esterilização. 


\section{Classificação geral - LVBPR:}

A média de adequação geral da LVBPR das seis EMEIs avaliadas após os sete acompanhamentos foi de $35,28 \%$, sendo classificado em grau de risco sanitário alto $(26-50 \%)$ de acordo com CECANE/UFRGS [13].

Na primeira aplicação da LVBPR a média de adequação das EMEIs foi de 37,03\%, sendo que do terceiro ao quinto acompanhamento houve uma redução de 4\% na média dos percentuais de adequação comparados ao primeiro acompanhamento, havendo uma similaridade entre os dados obtidos em todas as aplicações da lista (Figura 2).

As categorias que apresentaram maiores reduções no percentual de adequação da LVBPR foram relacionadas às edificações e instalações; higienização de equipamentos, móveis e utensilios; matéria-prima, ingredientes e embalagens e lactário.

Todas as categorias foram referidas com percentual de adequação médio menor que $10 \%$, destacando a categoria 7 (lactário), que apresentou apenas $0,83 \%$ de média na aplicação da LVBPR em todas as EMEIs avaliadas. Esta redução deve-se possivelmente ao fato de não haver padronização de POPs além da constante mudança dos manipuladores.

Figura 2. Percentual de adequação geral da lista de verificação em boas práticas reduzida das escolas municipais de educação infantil.

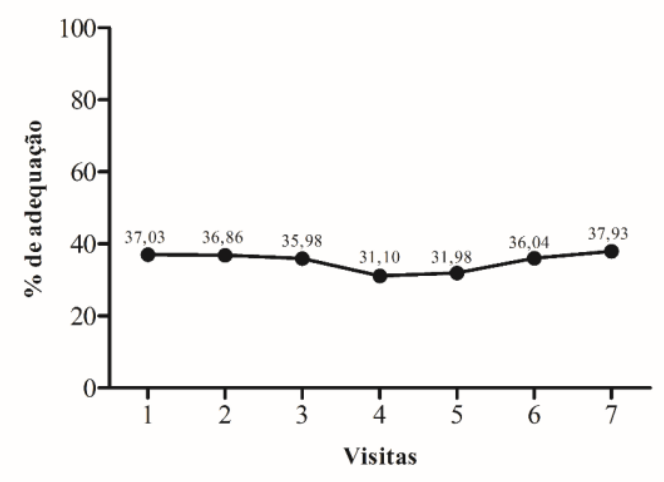

\section{Escolas Municipais de Ensino Fundamental (EMEFs)}

\section{Classificação geral - LVBPC:}

A média de adequação geral da LVBPC das seis EMEFs avaliadas foi de 37,79\% na aplicação inicial e 42,59\% na aplicação final, sendo classificadas em grau de risco sanitário alto (26-50\%) de acordo com o percentual de adequação do CECANE/UFRGS [13]. Da mesma forma Stedefeldt et al. [11], em seu estudo, constataram que o maior número de classificações de LVBP atribuída a UANEs, facilita a tomada de decisões e intervenções no intuito de corrigir e melhorar a pontuação final.

$\mathrm{Na}$ avaliação geral da LVBPC das EMEFs, entre as aplicações da lista, todas as UANEs apresentaram aumento nos percentuais de adequação (Figura 3), no entanto, a escola A obteve um aumento de $12,90 \%$, seguida da escola $C$ com $8,55 \%$.

As EMEFs A e C apresentaram aumento nas categorias relacionadas à higienização de instalações, equipamentos, móveis e utensílios; manipuladores de alimentos; documentação e registro. Enquanto somente a escola A apresentou aumento nas categorias relacionadas a edificações e instalações; armazenamento, transporte e exposição do alimento; manejo de resíduos e responsabilidade, e a escola $\mathrm{C}$ nas categorias referentes a matéria-prima, ingredientes e embalagens e preparação do alimento.

Apesar dos percentuais de adequação terem aumentado entre a aplicação inicial e final da LVBPC, os mesmos não fizeram com que as escolas avaliadas alterassem a classificação de risco sanitário [13]. 
Figura 3. Percentual de adequação geral da lista de verificação em boas práticas completa das escolas municipais de ensino fundamental.

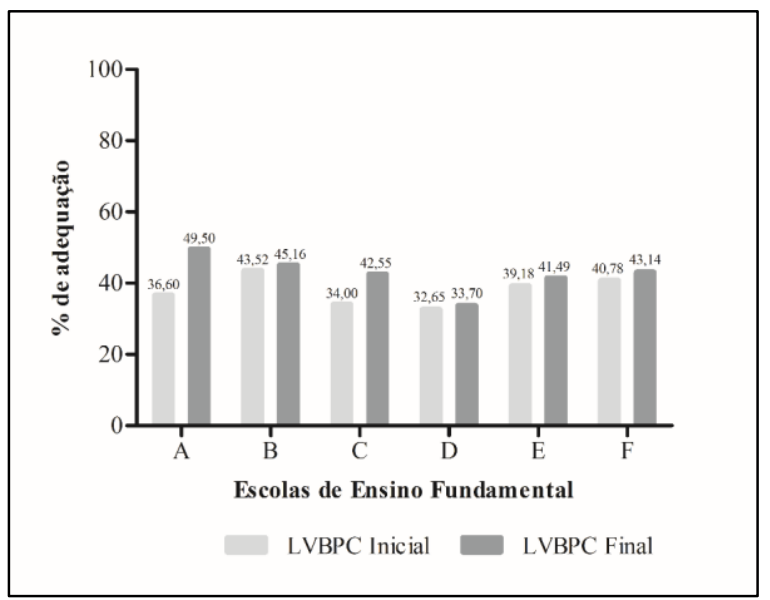

\section{Percentual de adequação da LVBPC por categoria:}

Na avaliação geral da LVBPC das seis EMEFs por categoria, a média da aplicação inicial foi de 40,18\% e aplicação final $43,12 \%$, ambas classificadas como alto risco sanitário (26-50\%) de acordo com o percentual de adequação do CECANE/UFRGS [13]. As categorias que apresentaram aumento no percentual de adequação entre a aplicação inicial e final da lista foram referentes ao manejo de resíduos; documentação e registro e higienização de instalações, equipamentos, móveis e utensílios, com aumento de $41,67 \%, 25 \%$ e $11,53 \%$, respectivamente (Tabela 3).

Tabela 3. Percentual médio de adequação da lista de verificação em boas práticas completa por categoria das escolas municipais de ensino fundamental.

\begin{tabular}{l|c|c}
\hline \multicolumn{1}{c|}{ Categoria } & $\begin{array}{c}\text { Aplicação } \\
\text { Inicial } \\
(\%)\end{array}$ & $\begin{array}{c}\text { Aplicação } \\
\text { Final } \\
(\%)\end{array}$ \\
\hline 1. Área externa & 33,33 & 33,33 \\
2. Edificações e instalações da área de preparo dos alimentos & 31,88 & 35,60 \\
3. Higienização de instalações, equipamentos, móveis e utensílios & 27,66 & 39,19 \\
4. Abastecimento de água & 96,67 & 93,33 \\
5. Manipuladores de alimentos & 40,79 & 41,83 \\
6. Matérias-primas, ingredientes e embalagens & 34,72 & 11,11 \\
7. Preparação do alimento & 41,27 & 43,89 \\
8. Armazenamento, Transporte e Exposição ao consumo de alimentos preparados & 28,61 & 39,17 \\
9. Manejo de resíduos & 22,22 & 63,89 \\
10. Controle integrado de pragas e vetores & 66,67 & 44,45 \\
11. Documentação e registro & 8,33 & 33,33 \\
12. Responsabilidade & 50,00 & 33,33 \\
\hline
\end{tabular}

As categorias que apresentaram aumento dos percentuais de adequação foram constatadas ao longo da pesquisa através de melhorias realizadas nas UANEs. Em relação ao manejo de resíduos todas as
EMEFs avaliadas possuíam lixeiras na aplicação inicial da lista, porém as mesmas não estavam em bom estado de conservação, dessa forma, na aplicação final foram fornecidas novas lixeiras pela SME para a área de 
manipulação de alimentos, justificando o aumento na referida categoria. Segundo Cardoso et al. [15], o manejo de resíduos é um fator preocupante, uma vez que compromete a higiene ambiental e, principalmente, expõe os escolares a situações de risco, visto que aumenta as chances de proliferação de pragas e vetores em UANEs. Por isso, o lixo deve ser retirado diariamente e/ou sempre que se fizer necessário, assim como as lixeiras devem ser mantidas em condições adequadas de higiene e conservação, e a cada esvaziamento deve ser realizado o processo de higienização ${ }^{[5]}$.

A formulação do MBP e POPs das EMEFs, também é fundamentada no Guia de Instruções Ferramentas para as Boas Práticas na Alimentação Escolar CECANE/UFRGS ${ }^{[13]}$ e, na categoria referente à documentação e registro, foi constatado que todas as escolas apresentavam MBP e POPs. Porém, assim como nas EMEIs, esses documentos não estavam disponíveis aos colaboradores e órgãos fiscalizadores na aplicação inicial da lista, de forma que muitos manipuladores de alimentos e diretores das UANEs desconheciam o seu conteúdo.

O MBP e POPs são importantes para manter a padronização do serviço, prevenindo possíveis erros no processo produtivo de alimentos [5]. $\mathrm{Na}$ aplicação final da LVBPC as EMEFs A e C adotaram medidas de adequação tornando-os acessíveis aos manipuladores de alimentos e órgãos sanitários.

As EMEFs A, C, D e E apresentaram aumento nos percentuais de adequação entre a aplicação inicial e final da lista na categoria higienização de instalações, equipamentos, móveis e utensílios. No entanto, as escolas C e D obtiveram um aumento de $31,86 \%$ e 23,07\%, respectivamente. Possivelmente este aumento no percentual de adequação tenha ocorrido porque, ao longo do acompanhamento, os manipuladores de alimentos foram sanando dúvidas sobre a higienização adequada das condições higiênico-estruturais das UANEs.

Importante destacar também que na aplicação inicial foi observada ausência de registros das operações de limpeza ou desinfecção de instalações e equipamentos, e na aplicação final já havia presença desses registros. As UANEs B e F mantiveram-se com os mesmos percentuais não havendo variação entre aplicação inicial e final da lista na referida categoria.
As categorias que obtiveram redução significativa no percentual de adequação entre a aplicação inicial e final da lista foram referentes a matérias-primas, ingredientes e embalagens, controle integrado de pragas e vetores e responsabilidade, com redução de 23,61\%, 22,22\% e 16,67\%, respectivamente. Essa redução deve-se as UANEs não adotarem medidas corretivas e preventivas, em uma série de itens avaliados.

Com relação à categoria matérias-primas, ingredientes e embalagens, as EMEFs $\mathrm{A}, \mathrm{B}, \mathrm{D}$ e $\mathrm{F}$ reduziram significativamente os percentuais de adequação entre a aplicação inicial e final da lista, visto que as escolas referidas não apresentaram percentual de adequação na aplicação final da lista. $\mathrm{O}$ recebimento não era inspecionado adequadamente e os gêneros alimentícios não eram recebidos em área protegida e limpa a fim de prevenir a contaminação cruzada.

Cabe ressaltar que nenhuma EMEF possuía termômetro para o controle da temperatura de recebimento desses alimentos. Além do que, nem sempre era possível observar o recebimento, pois havia dia específico para entrega desses gêneros alimentícios. De acordo com Cardoso et al. [15], a obtenção da matériaprima de boa qualidade e devidamente inspecionada é considerada requisito para a garantia da qualidade e da inocuidade do produto final, estando correlacionada com a saúde dos escolares.

\section{As EMEFs B e D reduziram} significativamente os percentuais de adequação entre a aplicação inicial e final da lista na categoria controle integrado de pragas e vetores. Eram realizadas desinsetizações e desratizações semestralmente em todas as EMEFs, porém não havia ações eficazes que impedissem a entrada desses animais, como o uso de telas milimétricas íntegras nas janelas e portas da área de manipulação de alimentos de algumas escolas. Ainda, quando apresentavam tela, as mesmas estavam danificadas. Essas inadequações podem acometer o processo produtivo de alimentos, comprometendo assim as condições higiênicas das refeições servidas aos escolares.

Em relação à responsabilidade, as EMEFs $\mathrm{C}$, $\mathrm{D}$ e E não apresentaram percentual de adequação na aplicação inicial e final da LVBPC. É importante destacar que são realizadas, no mínimo, duas capacitações anuais para os manipuladores de 
alimentos, ministradas pelas nutricionistas da SME e acadêmicos do curso de Nutrição da UNIPAMPA.

Evidenciou-se nesta pesquisa que, apesar das merendeiras serem convocadas a participar das capacitações, há uma baixa adesão das mesmas. No entanto, é relevante manter sempre profissionais devidamente capacitados de acordo com a realidade de cada escola. As demais categorias não apresentaram alterações no percentual de adequação entre as aplicações da LVBPC.

\section{Classificação geral - LVBPR:}

A média de adequação geral da LVBPR das seis EMEFs avaliadas após os sete acompanhamentos foi de $40,92 \%$, sendo classificado em risco sanitário alto (26-50\%) de acordo com o percentual de adequação do CECANE/UFRGS [13].

Na primeira aplicação da LVBPR a média de adequação das EMEFs avaliadas foi de 43,39\%, sendo que do quarto ao sexto acompanhamento houve uma redução de 5\% na média dos percentuais de adequação comparados ao primeiro acompanhamento. Isso demonstra uma similaridade entre os dados obtidos em todas as aplicações da lista (Figura 4).

As categorias que tiveram maiores reduções na LVBPR foram relacionadas às edificações e instalações da área de preparo dos alimentos; higienização de instalações, equipamentos, móveis e utensílios e matérias-primas, ingredientes e embalagens.

Todas as categorias citadas apresentaram percentual de adequação médio menor que $10 \%$, sendo que, a categoria 5 (matérias-primas, ingredientes e embalagens) apontou maior redução com 1,48\% de média na aplicação da LVBPR em todas as EMEFs.

No decorrer da pesquisa pode-se constatar que a responsabilidade e atenção nas referidas categorias foram reduzidas, isso pode justificar-se, tanto nas EMEFs quanto nas EMEIs, pela falta de padronização dos POPs e constante mudança de manipuladores.
Figura 4. Percentual de adequação geral da lista de verificação em boas práticas reduzida das escolas municipais de ensino fundamental.

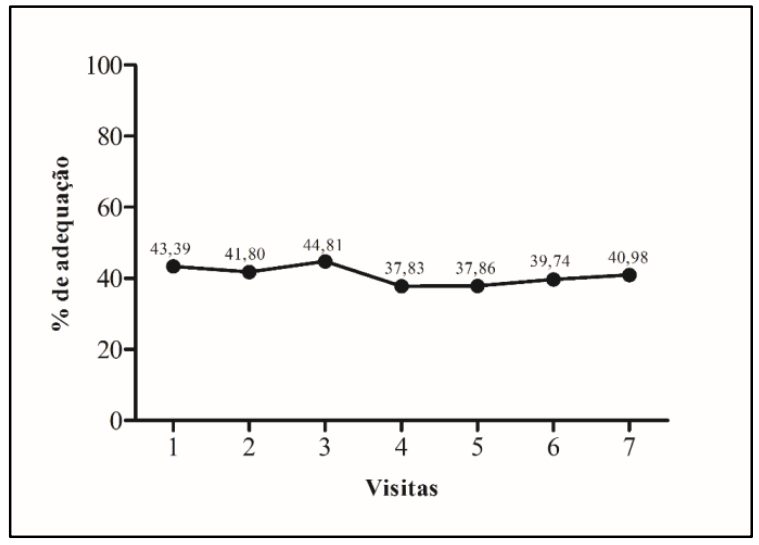

\section{CONCLUSÕES}

A partir da avaliação de 12 escolas públicas municipais evidenciou-se, por meio da aplicação das LVBPC e LVBPR, a inadequação das condições higiênicas das escolas municipais de educação infantil e das escolas municipais de ensino fundamental. Todas as escolas avaliadas foram classificadas como risco sanitário alto durante a pesquisa, o que pode comprometer a qualidade higiênico-sanitária das refeições servidas aos escolares.

A aplicação da LVBP específica para a realidade de cada UANE e o acompanhamento diário e/ou semanal possibilitaram um diagnóstico mais fidedigno. Cabe salientar que durante a pesquisa, não foram encontrados na literatura trabalhos acadêmicos com acompanhamento durante um período de tempo. Ainda, o estudo possibilitou um maior conhecimento das reais condições higiênicas das escolas públicas municipais.

Portanto, percebe-se a necessidade de ações preventivas, além de medidas de adequação dessas UANEs. Esta pesquisa corrobora a importância da escola no processo de educação e da alimentação escolar de crianças e adolescentes e reforça a necessidade de realizar novos estudos e atividades contínuas com essa população, dessa forma, será proposto o seguimento do estudo com intervenções, tendo em vista o diagnóstico obtido na presente pesquisa. 


\section{AGRADECIMENTOS}

À Secretaria Municipal de Educação e à Vigilância Sanitária Municipal do município que, em parceria, permitiram que o estudo fosse executado. Às unidades escolares participantes da pesquisa, aos diretores e responsáveis, bem como aos manipuladores de alimentos que possibilitaram que esse trabalho fosse realizado com êxito.

\section{REFERÊNCIAS}

[1] Cardoso RCV, Almeida RCC, Guimarães AG, Gões JAW, Santana AAC, Silva SA, et al. Avaliação da qualidade microbiológica de alimentos prontos para consumo servidos em escolas atendidas pelo Programa Nacional de Alimentação Escolar. Rev. Inst. Adolfo Lutz. 2010;69(2):20813.

[2] Issa RC, Moraes LF, Francisco RRJ, Santos LC, Anjos AFV, Pereira SCL. Alimentação escolar: planejamento, produção, distribuição e adequação. Rev. Panam. Salud Publica. 2014;35(2):96-103.

[3] Sturion GL, Silva MV, Ometto AMH, Furtuoso MCO, Pipitone MAP. Fatores condicionantes da adesão dos alunos ao Programa de Alimentação Escolar no Brasil. Rev. Nutr. 2005;18(2):167-81.

[4] Ministério da Educação (BR), Fundo Nacional de Desenvolvimento da Educação. Programa Nacional de Alimentação Escolar - Apresentação [internet]. Brasília; 2015 [acesso em 30 mar 2015]. Disponível em: http://www.fnde.gov.br/programas/alimentacao-escolar

[5] Ministério da Saúde (BR), Agência Nacional de Vigilância Sanitária. RDC no 216, de 15 de setembro de 2004. Dispõe sobre o Regulamento Técnico de Boas Práticas para Serviços de Alimentação. Diário Oficial União. 16 set 2004; Seção 1:25.

[6] Secretaria da Saúde (RS). Portaria no 78, de 30 de janeiro de 2009. Aprova a Lista de Verificação em Boas Práticas para Serviços de Alimentação, aprova Normas para Cursos de capacitação em Boas Práticas para Serviços de Alimentação e dá outras providências. Diário Oficial do Estado do Rio Grande do Sul. 28 jan 2009; Seção 1:35.

[7] Ministério da Saúde (BR), Agência Nacional de Vigilância Sanitária. Portaria no 817, de 10 de maio de 2013. Aprova as diretrizes nacionais para a elaboração e execução do projetopiloto de categorização dos serviços de alimentação para a Copa do Mundo FIFA 2014. Diário Oficial União. 13 mai 2013; Seção 1:44.
[8] Ministério da Saúde (BR), Secretaria de Vigilância em Saúde. Doenças Transmitidas por Alimentos - Descrição da Doença [internet]. Brasilia; 2015 [acesso em 13 abr 2015]. Disponível em: http://www.portalsaude.saude.gov.br

[9] Ministério da Saúde (BR), Secretaria de Vigilância em Saúde. Vigilância epidemiológica das doenças transmitidas por alimentos [internet]. Brasilia; 2014 [acesso em 11 mai 2015]. Disponível em: http://www.anrbrasil.org.br

[10] Silva BC, Fortuna JL. Condições higiênico-sanitárias na manipulação de alimentos, em cozinhas e cantinas de escolas públicas municipais de Mucuri, BA. Rev. Hig. Aliment. 2011;25(202/203):51-6.

[11] Stedefeldt E, Cunha DT, Silva Junior EA, Oliveira ABA. Instrumento de avaliação das Boas Práticas em Unidades de Alimentação e Nutrição Escolar: da concepção à validação. Rev. Ciênc. Saúde Colet. 2013;18(4):947-53.

[12] Mezzari MF, Ribeiro AB. Avaliação das condições higiênico-sanitárias da cozinha de uma escola municipal de Campo Mourão - Paraná. SaBios: Rev. Saúde e Biol. 2012;7(3):60-6.

[13] Centro Colaborador em Nutrição e Alimentação do Escolar, Fundo Nacional de Desenvolvimento da Educação - FNDE. Ferramentas para as Boas Práticas na Alimentação Escolar, versão 1.0 [internet]. Brasilia; 2012 [acesso em 25 mar 2015]. Disponível em: http://www.ufrgs.br/cecane

[14] Kochansky S, Pierozan MK, Mossi AJ, Treichel H, Cansian RL, Ghisleni CP, et al. Avaliação das condições microbiológicas de uma unidade de alimentação e nutrição. Rev. Alim. Nutr. 2009;20(4):663-8.

[15] Cardoso RCV, Góes JAW, Almeida RCC, Guimarães AG, Barreto DL, Silva SA, et al. Programa Nacional de Alimentação Escolar: há segurança na produção de alimentos em escolas de Salvador (Bahia)? Rev. Nutr. 2010;23(5):80111.

[16] Oliveira MN, Brasil ALD, Taddei JAAC. Avaliação das condições higiênico-sanitárias das cozinhas de creches públicas e filantrópicas. Rev. Ciênc. Saúde Colet. 2008;13(3):1051-60.

[17] Silva Júnior EA. Manual de Controle Higiênico-Sanitário em Serviços de Alimentação. 7.ed. São Paulo: Editora Varela; 2015. 